\title{
The association between ANKH promoter polymorphism and chondrocalcinosis is independent of age and osteoarthritis: results of a case-control study
}

\author{
Abhishek Abhishek ${ }^{1,2^{*}}$, Sally Doherty ${ }^{2}$, Rose Maciewicz ${ }^{3}$, Kenneth Muir ${ }^{4}$, Weiya Zhang ${ }^{2}$, Michael Doherty ${ }^{2}$ \\ and Anna M Valdes ${ }^{2}$
}

\begin{abstract}
Introduction: Chondrocalcinosis (CC) most commonly results from calcium pyrophosphate crystal deposition (CPPD). The objective of this study is to examine the association between candidate single-nucleotide polymorphisms (SNPs) and radiographic CC.

Methods: SNPs in ankylosis human (ANKH), high ferritin (HFE), tissue non-specific alkaline phosphatase (TNAP), ecto-neucleotide pyrophosphatase 1 (ENPP1), and transferrin (TE) genes were genotyped in participants of the Genetics of Osteoarthritis and Lifestyle (GOAL) and Nottingham Osteoarthritis Case-Control studies. Adjusted genotype odds ratio ( $\left(\mathrm{OR}_{\mathrm{GENOTYPE}}\right.$ ), the OR for association between one additional minor allele and $\mathrm{CC}$, was calculated and adjusted for age, gender, body mass index (BMI), and osteoarthritis $(\mathrm{OA})$ by using binary logistic regression. Statistical significance was set at $P \leq 0.003$ after Bonferroni correction for multiple tests.
\end{abstract}

Results: The $-4 \mathrm{bpG}>$ A polymorphism in the $5^{\prime}$ untranslated region (5' UTR) of ANKH associated with CC after Bonferroni correction. This was independent of age, gender, OA, and BMl; aOR GENOTYPE $(95 \%$ confidence interval, or CI) was 1.39 (1.14-1.69) $(P=0.001)$. rs 3045 and rs875525, two other SNPs in ANKH, associated with CC; aOR $\mathrm{RENONYPE}(95 \% \mathrm{Cl})$ values were $1.31(1.09-1.58)(P=0.005)$ and $1.18(1.03-1.35)(P=0.015)$, respectively; however, this was non-significant after Bonferroni correction.

Conclusions: This study validates the association between a functional polymorphism in the $5^{\prime}$ UTR of ANKH and CC and shows for the first time that this is independent of age and OA - the two key risk factors for CC. It shows that other SNPs in ANKH may also associate with CC. This supports the role of extracellular inorganic pyrophosphate in the pathogenesis of CC. The findings of this hospital-based study require replication in a community-based population.

\section{Introduction}

Chondrocalcinosis (CC) most commonly results from calcium pyrophosphate (CPP) crystal deposition (CPPD) [1]. CPPD may present as acute CCP crystal arthritis, CPPD with osteoarthritis (OA), chronic CPP crystal inflammatory arthritis, or asymptomatic CC [1]. Age, OA, diuretic use, and joint injury are recognized risk factors for CC $[1,2]$. Additionally, metabolic diseases that elevate extracellular

\footnotetext{
*Correspondence: docabhishek@gmail.com

'Department of Rheumatology, Addenbrooke's Hospital, Cambridge CB2 0QQ, UK ${ }^{2}$ Academic Rheumatology, University of Nottingham, Nottingham NG5 1PB, UK Full list of author information is available at the end of the article
}

pyrophosphate (ePPi) levels (hyperparathyroidism, hypomagnesemia, and hypophosphatasia), hemochromatosis, and familial predisposition are uncommon risk factors $[1,2]$. Though rare, familial predisposition is reported from several countries and different ethnic groups [3-9]. The pattern of inheritance is usually autosomal dominant. The main clinical phenotype is characterized by early onset (in the 20s or 30s) of acute CPP crystal arthritis with florid polyarticular $\mathrm{CC}$ and variable severity of accompanying structural arthritis/OA. However, a second phenotype with later onset in the sixth to seventh decades and oligoarticular CC that more closely resembles sporadic CPPD 
has also been reported [10]. This latter familial form may be more common than is recognized, the late onset of disease expression and geographic dispersal of families tending to mask such predisposition. An association with benign childhood fits appears unique to one UK family with early-onset polyarticular $\mathrm{CC}$, and the responsible gene-CC gene 2 (CCAL2) on chromosome 5p15-was first identified in this family [11]. Other kindreds with CC due to mutations at this locus [3] have been reported, and the responsible gene was subsequently identified as the ankylosis human (ANKH) gene [12]. The other reported locus in an American family with premature OA and associated CPPD (CCAL1) is on chromosome 8q [13], and a specific gene predisposing to CPPD at this site has not been identified.

Although several kindreds with familial CPPD are reported, the evidence for genetic contribution to sporadic $\mathrm{CC}$ is conflicting [3]. For example, the $-4 \mathrm{bpG}>\mathrm{A}$ transition in the $5^{\prime}$ untranslated region (5' UTR) of ANKH (which encodes the trans-membrane PPi transport protein ANKH) associated with $\mathrm{CC}$ in a study of $128 \mathrm{CC}$ cases and 475 healthy controls [14], whereas hereditary contribution to CC was not detected in a larger sibling study $(\mathrm{n}=1,841)$ [15]. Therefore, the objectives of this study were to validate the reported association between $-4 \mathrm{bpG}>$
A transition in the $5^{\prime}$ UTR of $A N K H$ and CC, to examine whether this is independent of other risk factors of $\mathrm{CC}$ such as age and OA, and to investigate whether other candidate single-nucleotide polymorphisms (SNPs) in genes involved in PPi metabolism-ANKH, tissue non-specific alkaline phosphatase (TNAP), and ectonucleotide pyrophosphatase 1 (ENPP1) (Figure 1)—or iron overload (for example, high ferritin and transferrin) associate with CC.

\section{Methods}

\section{Study design and participants}

The case-control study used data from the Genetics of Osteoarthritis and Lifestyle (GOAL) and Nottingham Osteoarthritis Case-Control (NOAC) studies [16,17] (Table 1). The GOAL study was approved by the Nottinghamshire Research Ethics Committee (UK). The NOAC study was approved by the North Nottinghamshire Research Ethics Committee and the Leicestershire, Northamptonshire, and Rutland Research Ethics Committee. All study participants gave written informed consent. These studies, originally set up to examine the genetics of large-joint OA, recruited Caucasians with (a) hip or knee OA severe enough to require joint replacement surgery or (b) no radiographic or clinical features of hip or knee OA $[16,17]$. All participants were

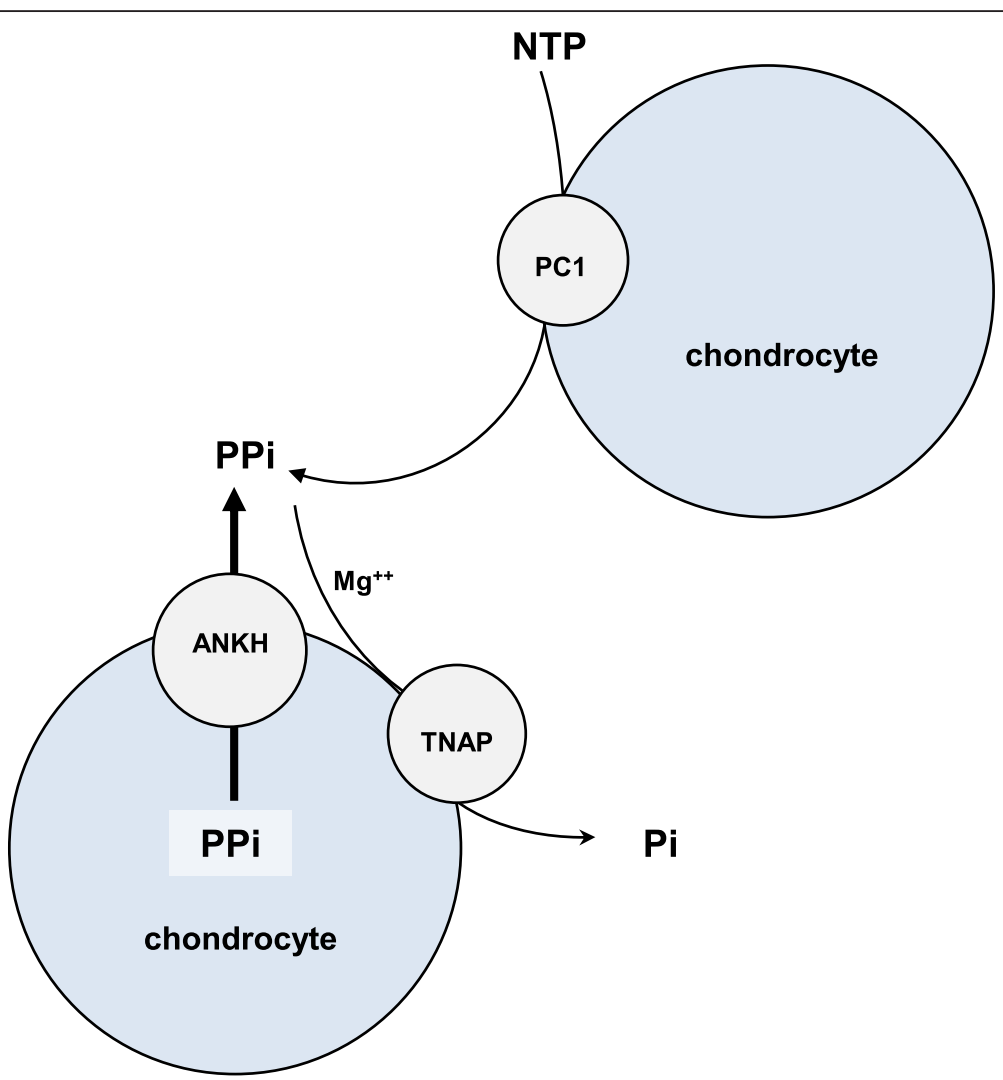

Figure 1 Extracellular pyrophosphate metabolism. ANKH, (progressive) ankylosis human; $\mathrm{Mg}^{++}$, magnesium; NTP, nucleotide tri-phosphate; PC1, plasma cell glycoprotein 1; Pi, phosphate; PPi, pyrophosphate; TNAP, tissue non-specific alkaline phosphatase. 
Table 1 Demographics of study participants

\begin{tabular}{|c|c|c|c|}
\hline & $\begin{array}{c}\text { CC present } \\
n=658\end{array}$ & $\begin{array}{l}\text { CC absent } \\
n=4,283\end{array}$ & $P$ \\
\hline Age in years, mean (SD) & $70.89(8.09)$ & $67.58(8.58)$ & $<0.001$ \\
\hline Female gender, number (percentage) & $325(49.4 \%)$ & $2,240(52.3 \%)$ & 0.165 \\
\hline Body mass index in $\mathrm{kg} / \mathrm{m}^{2}$, mean (SD) & $28.52(4.83)$ & $29.48(5.47)$ & $<0.001$ \\
\hline Knee or hip OA, number (percentage) & $584(90.0 \%)$ & 3,378 (79.0\%) & $<0.001$ \\
\hline
\end{tabular}

CC, chondrocalcinosis; OA, osteoarthritis; SD, standard deviation.

residents of Nottinghamshire, UK. Information about disease and demographic variables were collected at the study visit. Genomic DNA was extracted from the peripheral blood leukocytes by using standard protocols. GOAL study participants had radiographs of hands, knees, and pelvis; and the NOAC study participants had radiographs of the index knee or hip joint awaiting replacement. These radiographs were scored for $\mathrm{CC}$ at the knees, hips, wrists, and symphysis pubis and for metacarpophalangeal joint (MCPJ) calcification by a single trained observer (Sally Doherty).

\section{Cases and controls}

Cases were participants with $\mathrm{CC}$ at any joint, whereas controls did not have $\mathrm{CC}$ at any joint $\mathrm{x}$-rayed.

\section{Single-nucleotide polymorphism selection}

Seventeen SNPs were selected on the basis of published associations with various phenotypes (Table 2).

\section{Genotyping}

Genotyping was carried out at AstraZeneca laboratories in Macclesfield, UK, by using the Taqman method and at Kbioscience Ltd (Hertfordshire, UK) by using the Kompetitive Allele Specific PCR (KASPar) chemistry. All 17 SNPs were genotyped in the GOAL study. All selected SNPs in any gene which contained at least one SNP that associated with CC with an uncorrected $P \leq 0.10$ in the GOAL study were genotyped in the NOAC study participants.

\section{Covariates}

Data about age (years), height (centimeters), and weight (kilograms) were collected at the study visit. Height and weight were used to calculate body mass index (BMI) $\left(\mathrm{kg} / \mathrm{m}^{2}\right)$. OA was defined as knee or hip OA clinically severe enough to warrant consideration of joint replacement surgery.

Table 2 Association between all single-nucleotide polymorphisms and chondrocalcinosis in the Genetics of Osteoarthritis and Lifestyle study

\begin{tabular}{|c|c|c|c|c|c|c|}
\hline & \multirow[t]{2}{*}{ SNP } & \multirow[t]{2}{*}{ Reason for selection (association with): } & \multicolumn{2}{|c|}{ Minor allele frequency, \% } & \multirow{2}{*}{$\begin{array}{c}\mathrm{OR}_{\mathrm{GENOTYPE}} \\
(95 \% \mathrm{Cl})\end{array}$} & \multirow[t]{2}{*}{$P$} \\
\hline & & & $\mathrm{CC}+$ & $\mathrm{CC}-$ & & \\
\hline \multirow[t]{4}{*}{ ANKH } & $-4 \mathrm{bpG}>\mathrm{A} 5^{\prime}$ UTR & Chondrocalcinosis [14] & 11.0 & 8.2 & $1.36(1.07-1.73)$ & 0.013 \\
\hline & rs3045 & Rotator cuff tear and low intracellular PPi [18] & 12.7 & 10.1 & $1.28(1.02-1.60)$ & 0.030 \\
\hline & rs39968 & Parathyroid hormone level [19] & 28.1 & 30.9 & $0.89(0.76-1.05)$ & 0.160 \\
\hline & rs875525 & Parathyroid hormone level [19] & 28.1 & 25.6 & $0.89(0.76-1.04)$ & 0.152 \\
\hline \multirow[t]{2}{*}{ HFE } & rs1800562 & Hemochromatosis [20,21] & 7.8 & 7.8 & $1.01(0.77-1.33)$ & 0.937 \\
\hline & rs1799945 & Hemochromatosis $[20,21]$ & 17.1 & 14.7 & $1.20(0.99-1.46)$ & 0.070 \\
\hline \multirow[t]{2}{*}{ TNAP } & rs3200254 & Increased TNAP activity [22] & 11.1 & 11.0 & $0.99(0.79-1.25)$ & 0.957 \\
\hline & rs4654760 & Rotator cuff tear [18] & 6.7 & 6.6 & $1.01(0.76-1.35)$ & 0.955 \\
\hline \multirow[t]{5}{*}{ ENPP1 } & rs1044498 & Osteoarthritis [23] & 13.7 & 12.5 & $1.07(0.86-1.32)$ & 0.564 \\
\hline & rs28933977 & Osteoarthritis [23] & 3.7 & 4.1 & $0.81(0.55-1.20)$ & 0.826 \\
\hline & rs1800949 & Osteoarthritis [23] & 25.7 & 26.2 & $0.98(0.83-1.16)$ & 0.298 \\
\hline & rs858342 & Osteoarthritis [23] & 24.1 & 25.1 & $0.92(0.78-1.10)$ & 0.365 \\
\hline & rs943003 & Obesity [24] & 40.6 & 41.9 & $1.06(0.86-1.32)$ & 0.401 \\
\hline \multirow[t]{3}{*}{ Transferrin } & rs1799852 & Iron overload [25] & 8.2 & 9.4 & $0.89(0.69-1.15)$ & 0.372 \\
\hline & rs2280673 & Iron overload [25] & 34.7 & 35.4 & $0.97(0.83-1.12)$ & 0.664 \\
\hline & rs3811647 & Iron overload [25] & 36.5 & 34.7 & $1.08(0.92-1.26)$ & 0.348 \\
\hline
\end{tabular}

5' UTR, 5' untranslated region; ANKH, ankylosis human; CC, chondrocalcinosis; Cl, confidence interval; ENPP1, ecto-neucleotide pyrophosphatase 1; HFE, high ferritin; $\mathrm{OR}_{\mathrm{GENOTYPE}}$ genotype odds ratio; PPi, pyrophosphate; SNP, single-nucleotide polymorphism; TNAP, tissue non-specific alkaline phosphatase. 


\section{Statistical analysis}

Mean and standard deviation (SD) and number (percentage) were used for descriptive purposes. Chi-square test and student $t$ test were used to compare categorical and continuous variables. Cases with CC were compared with controls without CC. All SNPs were checked for HardyWeinberg equilibrium (HWE). Data from the GOAL and NOAC studies were pooled together for analyzing genetic risk. Genotype odds ratio $\left(\mathrm{OR}_{\mathrm{GENOTYPE}}\right)$-the OR for association between increasing number of minor alleles of an SNP and CC-was calculated. Binary logistic regression was used to calculate aOR $\mathrm{GENOTYPE}_{\text {( }}$ (95\% confidence interval, or $\mathrm{CI}$ ) adjusting for age (tertiles), gender, BMI (tertiles), and OA. Additionally, $\mathrm{OR}_{\mathrm{GENOTYPE}}$ was metaanalyzed with published studies by using fixed effects analysis given the lack of heterogeneity between studies. Meta-analyses were performed by using R V.2.13.1 [26]. Other analyses were carried out by using SPSSv14. Statistical significance for genetic association was set at $P \leq 0.003$ after application of Bonferroni correction for multiple tests. Linkage disequilibrium for the four $A N K H$ SNPs studied was estimated from unphased genotype data by using the Haploview 4.2 version [27].

\section{Results and discussion}

The descriptive characteristics of study participants are presented in Table 1. Three thousand one hundred fortyone GOAL and 1,800 NOAC study participants were included. The mean age (SD), number of females (percentage), and mean BMI (SD) of the GOAL study and NOAC study participants were 66.6 (7.9) and 70.5 (9.2) years, $1,520(48.4 \%)$ and 1,045 (58.1\%) women, and 29.3 (5.3) and $29.5(5.6) \mathrm{kg} / \mathrm{m}^{2}$, respectively. GOAL study participants were significantly younger $(P<0.001)$, were less likely to be female $(P<0.001)$, and had similar BMI $(P=0.22)$ compared with the NOAC study participants.

Six hundred fifty-eight (13.2\%) participants had CC at any site. All genotyped SNPs were in HWE. As TNAP571 [28] was a rare mutation in the GOAL study population (minor allele frequency $=0.01$ ), it was excluded from further analysis. Three ANKH and one HFE SNPs associated with $C C$ with an uncorrected $P \leq 0.10$ in the GOAL study population (Table 2). Thus, all ANKH (-4bpG > A 5' UTR, rs3045, rs39968, and rs875525) and HFE (rs1800562 and rs1799945) SNPs genotyped in the GOAL study were further genotyped in the NOAC study participants. The four ANKH SNPs were not in linkage disequilibrium (Table 3). Among the six SNPs genotyped in both the GOAL and NOAC studies, the $-4 \mathrm{bpG}>\mathrm{A} 5^{\prime}$ UTR of $A N K H$ associated with $\mathrm{CC}$ after adjustment for age, gender, BMI, and OA; aOR $_{\text {GENOTYPE }}$ was $1.39(1.14-1.69)(P=0.001)$ (Table 4). There was a trend toward an association between rs3045 and CC; aOR GENOTYPE $_{\text {was }} 1.31(1.09-1.58)(P=0.005)$; however, it was not statistically significant after application of Bonferroni correction (Table 4). The frequency of rare and common allelic variants in the ANKH and HFE SNPs genotyped in both the GOAL and NOAC studies is shown in an additional file (Additional file 1: Table S1).

\section{Comparison with published studies}

Two studies have reported on the association between CC and HFE SNPs [20,21]. Of these, one study reported genotype data about rs1800562, and rs1799945 without reporting full data on compound heterozygote numbers [20], whereas the other did not report detailed genotype data [21]. Therefore, the latter study was not included in the meta-analysis. In a meta-analysis of the data of the present study and of the study by Alizadeh et al. [20], the values for pooled $\mathrm{OR}_{\mathrm{GENOTYPE}}(95 \% \mathrm{CI})$ for association between rs1799945 and rs1800562 and CC were $1.20(1.04-1.39)(P=0.015)$ and $1.08(0.88-1.33)(P=$ $0.445)$, respectively. Similarly, the results of the present study and the previous study that reported an association between CC and -4bpG > A transition in the 5' UTR of ANKH were meta-analyzed [14]. The pooled OR $_{\text {GENOTYPE }}(95 \% \mathrm{CI})$ was $1.36(1.13-1.61)(P=0.001)$.

The present study confirms the association between CC and $-4 \mathrm{bpG}>\mathrm{A}$ transition in the $5^{\prime}$ UTR of $A N K H$. It is the first study to show that this association is independent of age and $\mathrm{OA}$, which are the two major established risk factors of CC. This study also raises the possibility that other SNPs in ANKH (for example, rs3045) may also associate with CC. However, in keeping with previous reports, there was no association between SNPs in TNAP or ENPP1 and CC [29].

$A N K H$ encodes a multipass transmembrane protein $(\mathrm{ANKH})$ in joints and other tissues and participates in the export of intracellular PPi [30,31]. PPi cannot diffuse across cell membranes passively, and ANKH is the principal way in which intracellular PPi reaches the extracellular environment. ANKH-mediated control of PPi levels regulates tissue calcification and susceptibility to arthritis [30,31]. The autosomal dominant mutations in $A N K H$ are thought to confer a gain in PPi transport function leading to increased extracellular PPi levels $[14,32]$. Functional assays show that the $-4 \mathrm{bpG}>\mathrm{A}$ transition in the 5' UTR of ANKH reduces intracellular PPi (a surrogate for increased transcellular PPi export) and increases ANKH expression in vitro [14,18]. The minor alleles of rs3045 also result in lower intracellular PPi levels in vitro, providing external validity to our finding of a possible association between this polymorphism and CC [18]. These two SNPs are not in linkage disequilibrium. The minor allele frequency for the $-4 \mathrm{bpG}>\mathrm{A}$ transition in 5' UTR of ANKH and rs3045 is higher in this study than that in the multi-ethnic 1000 Genomes Project. (See Additional file 2: Table S2 for genotype frequencies of the selected SNPs in the 1000 Genomes Project). This may 
Table 3 Linkage disequilibrium between the genotyped single-nucleotide polymorphisms in ankylosis human (ANKH) gene

\begin{tabular}{llll}
\hline Locus 1 & Locus 2 & D' $^{\prime}$ & $\mathbf{r}^{\mathbf{2}}$ \\
\hline rs39968 & rs3045 & 0.746 & 0.028 \\
rs39968 & rs875525 & 0.268 & 0.011 \\
rs39968 & $-4 \mathrm{bpg}>$ A 5' UTR & 0.076 & 0.001 \\
rs3045 & rs875525 & 0.826 & 0.226 \\
rs3045 & $-4 \mathrm{bpg}>$ A 5' UTR & 0.625 & 0.004 \\
rs875525 & $-4 \mathrm{bpg}>$ A 5' UTR & 0.448 & 0.006 \\
\hline
\end{tabular}

5' UTR, 5' untranslated region.

explain, in part, why CPPD is more common in Caucasians than in other ethnicities.

Though not statistically significant, results from the data suggest that rs1799945 (HFE SNP associated with smaller iron overload), but not rs1800562 (HFE SNP associated with greater iron overload), may associate with CC. Similar findings have been reported previously [20]. The lack of association between homozygosity for minor allele at rs1800562 and CC may be due to a channeling bias (that is, patients with hemochromatosis are excluded from these studies).

This is the largest reported study of genetic risk factors for CC. This study has several strengths. First, the analysis of genetic risk was adjusted for factors that associate with $\mathrm{CC}$, specifically age and $\mathrm{OA}$, and also for gender, which associates with iron overload. Moreover, correction for multiple testing was applied to reduce the chances of a type I error. However, this study has several caveats. First, this is a hospital-based study carried out by reconstituting cases and controls within cohorts assembled primarily to examine risk factors for knee or hip OA within the East Midlands region of the UK. Cases with mild to moderate large-joint OA were not included. The study sample therefore does not resemble a communitybased population and is restricted to one area of the country. Moreover, as more than $78 \%$ of participants had severe large-joint $\mathrm{OA}$, the results may be confounded by their OA status. However, to minimize any confounding and to improve the generalizability of these findings, we have adjusted for OA at the knee and hip. Second, participants of the NOAC study did not have the same extensive radiographic phenotyping of $\mathrm{CC}$ as participants of the GOAL study. As a result, some NOAC study participants who may have $\mathrm{CC}$ at distant joints without $\mathrm{CC}$ at the joint to be replaced will be misclassified as 'CC negative' controls. This misclassification is likely to minimize the genetic association and does not invalidate the genetic associations observed in this study.

\section{Conclusions}

This study validates an established genetic association with $\mathrm{CC}$ and shows that this is independent of age and OA. This study also raises the possibility that other SNPs in $A N K H$ associate with CC. Larger studies with greater power are required to confirm these findings. Finally, the findings of this study derived from a hospital-based cohort warrant confirmation in a community-based population including cases with mild to moderate disease and in other countries.

Table 4 Association between chondrocalcinosis and single-nucleotide polymorphisms in the combined dataset

\begin{tabular}{|c|c|c|c|c|c|c|c|c|}
\hline & \multirow{2}{*}{$\begin{array}{l}\text { Common } \\
\text { allele }\end{array}$} & \multirow{2}{*}{$\begin{array}{l}\text { Rare } \\
\text { allele }\end{array}$} & \multicolumn{2}{|c|}{ MAF, \% } & \multirow{2}{*}{$\begin{array}{c}\text { OR }_{\text {GENOTYPE }} \\
(95 \% \mathrm{Cl})\end{array}$} & \multirow[t]{2}{*}{$P$} & \multirow{2}{*}{$\begin{array}{c}\mathrm{aOR}_{\text {GENOTYPE }} \\
(95 \% \mathrm{Cl})\end{array}$} & \multirow[t]{2}{*}{$P$} \\
\hline & & & $\overline{\mathrm{CC}+}$ & $\overline{\mathrm{CC}-}$ & & & & \\
\hline$-4 \mathrm{bpG}>\mathrm{A} 5^{\prime}$ UTR & G:G & $A: A$ & 10.6 & 8.1 & $1.36(1.12-1.65)$ & 0.002 & $1.39(1.14-1.69)$ & 0.001 \\
\hline rs3045 & $\mathrm{T}: \mathrm{T}$ & $\mathrm{C}: \mathrm{C}$ & 12.4 & 9.9 & $1.29(1.08-1.55)$ & 0.006 & $1.31(1.09-1.58)$ & 0.005 \\
\hline rs39968 & $C: C$ & $\mathrm{~T}: \mathrm{T}$ & 28.8 & 30.8 & $0.91(0.80-1.04)$ & 0.155 & $0.91(0.80-1.04)$ & 0.156 \\
\hline rs875525 & $\mathrm{C}: \mathrm{C}$ & $\mathrm{T}: \mathrm{T}$ & 28.1 & 25.0 & $1.18(1.03-1.34)$ & 0.014 & $1.18(1.03-1.35)$ & 0.015 \\
\hline rs1800562 & G:G & $A: A$ & 8.3 & 7.6 & $1.10(0.89-1.36)$ & 0.386 & $1.13(0.91-1.40)$ & 0.273 \\
\hline rs1799945 & $C: C$ & G:G & 16.9 & 14.6 & $1.19(1.02-1.39)$ & 0.032 & $1.18(1.00-1.38)$ & 0.047 \\
\hline
\end{tabular}

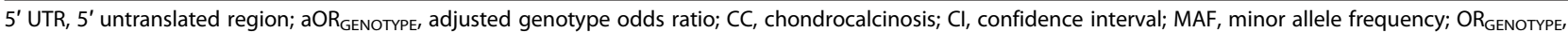
genotype odds ratio. 


\section{Additional files}

Additional file 1: Table S1. Genotypes frequencies of ankylosis human (ANKH) and high ferritin (HFE) single-nucleotide polymorphisms (SNPs) in Genetics of Osteoarthritis and Lifestyle (GOAL) and Nottingham Osteoarthritis Case-Control (NOAC) studies.

Additional file 2: Table S2. Published minor allele frequency (MAF) of selected single-nucleotide polymorphisms (SNPs) from the 1000 Genomes Project phase 1. Genotype data from 1,094 individuals from across the world (http://www.1000genomes.org/node/506)

\section{Abbreviations}

5' UTR: 5' untranslated region; ANKH: ankylosis human; BMl: body mass index; CC: chondrocalcinosis; CCAL (1 or 2): chondrocalcinosis (1 or 2) gene; Cl: confidence interval; CPP: calcium pyrophosphate crystal; CPPD: calcium pyrophosphate crystal deposition; ENPP1: ectonucleotide pyrophosphatase 1; GOAL: Genetics of Osteoarthritis and Lifestyle; HFE: high ferritin; HWE: HardyWeinberg equilibrium; MCPJ: metacarpophalangeal joint; NOAC: Nottingham Osteoarthritis Case-Control; OA: osteoarthritis; OR ratio; PPi: pyrophosphate; SD: standard deviation; SNP: single-nucleotide polymorphism; TNAP: tissue non-specific alkaline phosphatase.

\section{Competing interests}

$\mathrm{RM}$ is an employee of AstraZeneca (London, UK), owns shares in that company, and was involved as a scientific collaborator in the GOAL study. She is named on a patent application for a gene associated with osteoarthritis. The other authors declare that they have no competing interests. AstraZeneca had no role in the study design, data analysis, or drafting of the manuscript.

\section{Authors' contributions}

$A A, R M$, and WZ were involved in study conception and design and in analysis and interpretation of the data. KM and MD were involved in study conception and design and in acquisition, analysis, and interpretation of the data. AMV was involved in study conception and design and in acquisition, analysis, and interpretation of the data and carried out the meta-analysis. SD was involved in study conception, data acquisition, and radiographic scoring. All authors were involved in drafting the article or revising it for important intellectual content. All authors read and approved the final version of the manuscript.

\section{Authors' information}

$\mathrm{AMV}$ and MD are joint senior authors.

\section{Acknowledgments}

AstraZeneca UK funded the GOAL study sample and data collection. The Arthritis Research Council provided infrastructure support during the GOAL study (grant 14581) and for part of the NOAC study. Genotyping for the NOAC study was funded by the EU FP7 large collaborative project grant 200800 TREAT-OA

\section{Author details}

${ }^{1}$ Department of Rheumatology, Addenbrooke's Hospital, Cambridge CB2 0QQ, UK. ${ }^{2}$ Academic Rheumatology, University of Nottingham, Nottingham NG5 1PB, UK. ${ }^{3}$ Respiratory and Inflammation iMed, AstraZeneca, Mölndal SE-431 83, Sweden. ${ }^{4}$ Health Sciences Research Institute, University of Warwick, Warwick CV4 7AL, UK.

Received: 21 September 2013 Accepted: 24 January 2014 Published: 27 January 2014

\section{References}

1. Zhang W, Doherty M, Bardin T, Barskova V, Guerne PA, Jansen TL, Leeb BF, Perez-Ruiz F, Pimentao J, Punzi L: European league against rheumatism recommendations for calcium pyrophosphate deposition. Part I: terminology and diagnosis. Ann Rheum Dis 2011, 70:563-570.

2. Richette P, Bardin T, Doherty M: An update on the epidemiology of calcium pyrophosphate dihydrate crystal deposition disease. Rheumatology (Oxford) 2009, 48:711-715.

3. Abhishek A, Doherty M: Pathophysiology of articular chondrocalcinosis-role of ANKH. Nat Rev Rheumatol 2011, 7:96-104.
4. Andrew LJ, Brancolini V, de la Pena LS, Devoto M, Caeiro F, Marchegiani R, Reginato A, Gaucher A, Netter P, Gillet P, Loeuille D, Prockop DJ, Carr A Wordsworth BF, Lathrop M, Butcher S, Considine E, Everts K, Nicod A, Walsh S, Williams CJ: Refinement of the chromosome $5 p$ locus for familial calcium pyrophosphate dihydrate deposition disease. Am J Hum Genet 1999, 64:136-145.

5. Béjia I, Rtibi I, Touzi M, Zrour S, Younes M, Naceur B: Familial calcium pyrophosphate dihydrate deposition disease. A Tunisian kindred. Joint Bone Spine 2004, 71:401-408.

6. Gaudreau A, Camerlain M, Pibarot ML, Beauregard G, Lebrun A, Petitclerc C: Familial articular chondrocalcinosis in Quebec. Arthritis Rheum 1981, 24:611-615.

7. Hamza M, Meddeb N, Bardin T: Hereditary chondrocalcinosis in a Tunisian family. Clin Exp Rheumatol 1992, 10:43-49.

8. Hamza M, Ayed K, Bardi R, Gebuhrer L, Betuel H, Bardin T, Plaetke R, Lathrop M: HLA-antigens in a Tunisian familial chondrocalcinosis. Dis Markers 1990, 8:109-112.

9. Reginato AJ, Hollander JL, Martinez V, Valenzuela F, Schiapachasse V, Covarrubias E, Jacobelli S, Arinoviche R, Silcox D, Ruiz F: Familial chondrocalcinosis in the Chiloe Islands, Chile. Ann Rheum Dis 1975, 34:260-268.

10. Riestra JL, Sanchez A, Rodriguez-Valverde V, Alonso JL, de la Hera M, Merino J: Radiographic features of hereditary articular chondrocalcinosis. A comparative study with the sporadic type. Clin Exp Rheumatol 1988, 6:369-372.

11. Doherty M, Hamilton E, Henderson J, Misra H, Dixey J: Familial chondrocalcinosis due to calcium pyrophosphate dihydrate crystal deposition in English families. Br J Rheumatol 1991, 30:10-15.

12. Williams CJ, Zhang Y, Timms A, Bonavita G, Caeiro F, Broxholme J, Cuthbertson J, Jones Y, Marchegiani R, Reginato A, Russell RG, Wordsworth BP, Carr AJ, Brown MA: Autosomal dominant familial calcium pyrophosphate dihydrate deposition disease is caused by mutation in the transmembrane protein ANKH. Am J Hum Genet 2002, 71:985-991.

13. Baldwin $C T$, Farrer LA, Adair R, Dharmavaram $R$, Jimenez $S$, Anderson $L$ : Linkage of early-onset osteoarthritis and chondrocalcinosis to human chromosome 8q. Am J Hum Genet 1995, 56:692-697.

14. Zhang Y, Johnson K, Russell RG, Wordsworth BP, Carr AJ, Terkeltaub RA, Brown MA: Association of sporadic chondrocalcinosis with a -4-basepair G-to-A transition in the $5^{\prime}$-untranslated region of ANKH that promotes enhanced expression of ANKH protein and excess generation of extracellular inorganic pyrophosphate. Arthritis Rheum 2005, 52:1110-1117

15. Zhang W, Neame R, Doherty S, Doherty M: Relative risk of knee chondrocalcinosis in siblings of index cases with pyrophosphate arthropathy. Ann Rheum Dis 2004, 63:969-973.

16. Valdes AM, De Wilde G, Doherty SA, Lories RJ, Vaughn FL, Laslett LL, Maciewicz RA, Soni A, Hart DJ, Zhang W: The lle585Val TRPV1 variant is involved in risk of painful knee osteoarthritis. Ann Rheum Dis 2011, 70:1556-1561.

17. Robertson J, Zhang W, Liu JJ, Muir KR, Maciewicz RA, Doherty M: Radiographic assessment of the index to ring finger ratio (2D:4D) in adults. J Anat 2008, 212:42-48.

18. Peach CA, Zhang Y, Dunford JE, Brown MA, Carr AJ: Cuff tear arthropathy: evidence of functional variation in pyrophosphate metabolism genes. Clin Orthop Relat Res 2007, 462:67-72.

19. Vistoropsky Y, Keter M, Malkin I, Trofimov S, Kobyliansky E, Livshits G: Contribution of the putative genetic factors and ANKH gene polymorphisms to variation of circulating calciotropic molecules, PTH and BGP. Hum Mol Genet 2007, 16:1233-1240

20. Alizadeh BZ, Njajou OT, Hazes JM, Hofman A, Slagboom PE, Pols HA, van Duijn CM: The H63D variant in the HFE gene predisposes to arthralgia, chondrocalcinosis and osteoarthritis. Ann Rheum Dis 2007, 66:1436-1442.

21. Timms AE, Sathananthan R, Bradbury L, Athanasou NA, Wordsworth BP, Brown MA: Genetic testing for haemochromatosis in patients with chondrocalcinosis. Ann Rheum Dis 2002, 61:745-747.

22. Goseki-Sone M, Sogabe N, Fukushi-lrie M, Mizoi L, Orimo H, Suzuki T, Nakamura H, Orimo $\mathrm{H}$, Hosoi T: Functional analysis of the single nucleotide polymorphism $(787 \mathrm{~T}>\mathrm{C})$ in the tissue-nonspecific alkaline phosphatase gene associated with BMD. J Bone Miner Res 2005, 20:773-782.

23. Suk EK, Malkin I, Dahm S, Kalichman L, Ruf N, Kobyliansky E, Toliat M, Rutsch F, Nürnberg P, Livshits G: Association of ENPP1 gene polymorphisms with 
hand osteoarthritis in a Chuvasha population. Arthritis Res Ther 2005, 7:R1082-R1090.

24. Valli-Jaakola K, Suviolahti E, Schalin-Jäntti C, Ripatti S, Silander K, Oksanen L, Salomaa V, Peltonen L, Kontula K: Further evidence for the role of ENPP1 in obesity: association with morbid obesity in Finns. Obesity (Silver Spring) 2008, 16:2113-2119.

25. Benyamin B, McRae AF, Zhu G, Gordon S, Henders AK, Palotie A, Peltonen L, Martin NG, Montgomery GW, Whitfield JB, Visscher PM: Variants in TF and HFE explain approximately $40 \%$ of genetic variation in serum-transferrin levels. Am J Hum Genet 2009, 84:60-65.

26. R Development Core Team: R: A Language and Environment for Statistical Computing. Vienna, Austria: R Foundation for Statistical Computing; 2010 . Retrieved from http://www.R-project.org.

27. Barrett JC, Fry B, Maller J, Daly MJ: Haploview: analysis and visualization of LD and haplotype maps. Bioinformatics 2005, 21:263-265.

28. Fauvert D, Brun-Heath I, Lia-Baldini AS, Bellazi L, Taillandier A, Serre JL, de Mazancourt P, Mornet E: Mild forms of hypophosphatasia mostly result from dominant negative effect of severe alleles or from compound heterozygosity for severe and moderate alleles. BMC Med Genet 2009, 10:51.

29. Zhang Y, Brown MA, Peach C, Russell G, Wordsworth BP: Investigation of the role of ENPP1 and TNAP genes in chondrocalcinosis. Rheumatology (Oxford) 2007, 46:586-589.

30. Ho AM, Johnson MD, Kingsley DM: Role of the mouse ank gene in control of tissue calcification and arthritis. Science 2000, 289:265-270.

31. Gurley KA, Reimer RJ, Kingsley DM: Biochemical and genetic analysis of ANK in arthritis and bone disease. Am J Hum Genet 2006, 79:1017-1029.

32. Pendleton A, Johnson MD, Hughes A, Gurley KA, Ho AM, Doherty M, Dixey J, Gillet P, Loeuille D, McGrath R, Reginato A, Shiang R, Wright G, Netter P, Williams C, Kingsley DM: Mutations in ANKH cause chondrocalcinosis. Am J Hum Genet 2002, 71:933-940.

doi:10.1186/ar4453

Cite this article as: Abhishek et al:: The association between $A N K H$ promoter polymorphism and chondrocalcinosis is independent of age and osteoarthritis: results of a case-control study. Arthritis Research \& Therapy 2014 16:R25.

\section{Submit your next manuscript to BioMed Central and take full advantage of:}

- Convenient online submission

- Thorough peer review

- No space constraints or color figure charges

- Immediate publication on acceptance

- Inclusion in PubMed, CAS, Scopus and Google Scholar

- Research which is freely available for redistribution 